\title{
Urine Glycoprotein Crystal Growth Inhibitors Evidence for a Molecular Abnormality in Calcium Oxalate Nephrolithiasis
}

\author{
Y. Nakagawa, V. Abram, J. H. Parks, H. S.-H. Lau, J. K. Kawooya, and F. L. Coe \\ Nephrology Section, and Department of Biochemistry, The University of Chicago, Chicago, Illinois 60637
}

\begin{abstract}
One reason that some people are prone to calcium oxalate nephrolithiasis is that they produce urine that is subnormal in its ability to inhibit the growth of calcium oxalate crystals. We have identified in human urine a glycoprotein (GCI) that inhibits calcium oxalate crystal growth strongly, and at low concentrations $\left(10^{-7} \mathrm{M}\right)$; in this study, we have isolated GCI molecules from the urine of normal people and patients with calcium oxalate stones. GCI from stone formers is abnormal in three ways: (1) it contains no detectable $\boldsymbol{\gamma}$-carboxyglutamic acid (Gla), whereas normal GCI contains 2-3 residues of Gla per mole; (2) about half of the GCI in urine of patients inhibits crystal growth 4-20 times less than normal GCI as judged by its performance in a kinetic growth assay, in vitro; (3) at the air-water interface, patient GCI has a film collapse pressure approximately half of normal. GCI molcules from the urine of patients with calcium oxalate nephrolithiasis are intrinsically abnormal, and these abnormalities could play a role in the genesis of stones.
\end{abstract}

\section{Introduction}

Human urine inhibits the growth of calcium oxalate monohydrate crystals. Added at dilutions of even 1:100, urine greatly slows the rate at which calcium oxalate monohydrate crystals grow in a metastably supersaturated calcium oxalate solution (1-6). The upper limit of metastability for calcium oxalate is higher in urine than in simple salt solutions (7), because urine inhibits the process of nucleation-i.e., the transformation of solution ions into a solid phase-and slows the growth of very small nuclei so they cannot be detected.

Although citrate and inorganic pyrophosphate are present in urine at concentrations sufficient to inhibit calcium oxalate monohydrate crystal growth $-0.5-1 \mathrm{mM}$ and $1-2 \mu \mathrm{M}$, respectively, they account for little of the crystal growth inhibition produced by urine (2). Exhaustive dialysis of urine removes both molecules, yet reduces crystal growth inhibition by only a few percent (1). Orthophosphate administered orally increases urine pyrophosphate level, and inhibits the crystal growth in urine of brushite, but not calcium oxalate monohydrate (8).

The molecules that account for most of the inhibitory effects

An abstract of this work has been submitted to the Association of American Physicians spring meeting 1985, which will be presented 6 May, 1985.

Address reprint requests to Dr. Nakagawa, Nephrology Section, Box 28, University of Chicago, Pritzker School of Medicine. 1985

Received for publication 4 April 1985 and in revised form 3 June

J. Clin. Invest.

(c) The American Society for Clinical Investigation, Inc.

$0021-9738 / 85 / 10 / 1455 / 08 \quad \$ 1.00$

Volume 76, October 1985, 1455-1462 of urine on calcium oxalate monohydrate crystal growth include glycosaminoglycans (9) and acidic glycoproteins (GCI) ${ }^{1}$ of unusual properties (10) that we have purified from a culture of human renal cells (11), human urine (12), and rat urine and kidney tissue (13). The crystal growth inhibitor moleculeswhich we wish to abbreviate as GCI molecules-appear to account for a considerable proportion of the inhibitory effects of urine $(12,13)$, and are the focus of this report.

We $(1)$ and others $(5,9,14)$ have found that urine from stone-forming patients inhibits calcium oxalate crystal growth less than normal urine, and have reasoned that patients who form stones may do so in part because they produce GCI molecules that are less inhibitory than normal ones, or excrete intrinsically normal $\mathrm{GCI}$ molecules in abnormally small quantities. We present here evidence for the former: compared with normal GCI molecules, GCI molecules isolated from the urine of patients with nephrolithiasis are less effective as inhibitors; they are also abnormal in their composition, and in their physical properties at the air-water interface.

\section{Methods}

Patients and normal subjects. We studied 20 normal people (11 women) and 17 consecutive patients ( 7 women) with recurrent calcium oxalate nephrolithiasis (Table I). The ages $( \pm$ SEM) of the women normals and patients $(29 \pm 5$ vs. $41 \pm 19)$ and the men normals and patients $(31 \pm 8$ vs. $39 \pm 8$ ) were not different. Patients had no known systemic disease as a cause of stones (15-17) except for idiopathic hypercalciuria (15), nor were any taking medications. A single 24-h urine was collected (thymol was used as a preservative) while each person ate a free choice diet. Creatinine was measured as a marker for completeness of collection (18). Each urine sample was processed separately to isolate GCI molecules; but the small amounts of inhibitor available from any individual made it necessary to perform amino acid and carbohydrate analyses, air waterinterface film balance studies, and kinetic assays of the crystal adsorption coefficient on pooled materials from patients and normals.

Isolation of urine inhibitor. Inhibitors were isolated using a modified version of a method developed in this laboratory (12). A 24-h urine sample was diluted four times in distilled water to lower its ionic strength below 10 milli-Siemens $/ \mathrm{cm}(\mathrm{mS} / \mathrm{cm})$ (equivalent to $0.05 \mathrm{M} \mathrm{NaCl}$ ). DEAECellulose equilibrated in $0.05 \mathrm{M}$ Tris- $\mathrm{HCl}-0.05 \mathrm{M} \mathrm{NaCl}(\mathrm{pH} 7.3$ ) was added and stirred for $30 \mathrm{~min}$ at room temperature. The slurry was filtered through a sintered glass filter, the cake was washed with 4 liters of 0.05 $\mathrm{M}$ Tris- $\mathrm{HCl}-0.05 \mathrm{M} \mathrm{NaCl}$ (pH 7.3), and the inhibitor was eluted with $400 \mathrm{ml}$ of $0.05 \mathrm{M}$ Tris-HCl-0.4 M NaCl (pH 7.3). To dissociate aggregated inhibitors to a monomeric form, the eluate was adjusted to a final concentration of $0.05 \mathrm{M}$ EDTA, pH 7.9, and kept at $4^{\circ} \mathrm{C}$ for $4 \mathrm{~d}(11,12)$. After EDTA incubation, the solution was dialyzed against 12 liter of deionized water for $24 \mathrm{~h}$ with one change.

The dialyzed solution was applied to a DEAE-cellulose column and eluted with a linear $\mathrm{NaCl}$ gradient from 0.1 to $0.4 \mathrm{M}$ in $0.05 \mathrm{M}$ Tris buffer (pH 7.3). The GCI molecules exhibit micro-heterogeneity (12), in

1. Abbreviations used in this paper: GCI, glycoprotein crystal growth inhibitor; Gla, $\gamma$-carboxyglutamic acid. 
eluting from the DEAE-cellulose column in up to four separate peaks that fall into the ionic strength ranges of 12-22 mS/cm, 23-29 mS, 30$39 \mathrm{mS}$, and $40-45 \mathrm{mS}$. Not every urine sample yielded all four peaks (Table I), but all of the inhibitory material that could be eluted from the column was in one of the four regions as a peak. We collected the four

Table I. Distribution of GCI Fractions in Patients and Normal Subjects

\begin{tabular}{lllll}
\hline Age & A & B & C & D \\
\hline & $\%$ & $\%$ & $\%$ & $\%$
\end{tabular}

\section{Men patients}

$\begin{array}{lrrrr}48 & 28.8 & 19.4 & 17.1 & 34.7 \\ 48 & 25.0 & 32.5 & 33.1 & 9.4 \\ 28 & 22.1 & 28.3 & 33.7 & 15.8 \\ 38 & 47.5 & 8.9 & 19.6 & 23.9 \\ 52 & 20.1 & 46.6 & 25.8 & 7.5 \\ 43 & 37.0 & 34.7 & 22.1 & 6.3 \\ 46 & 18.4 & 25.3 & 48.6 & 7.6 \\ 32 & 19.9 & 30.3 & 36.9 & 12.9 \\ 38 & 12.9 & 40.2 & 42.3 & 4.5 \\ 31 & 14.6 & 23.5 & 38.4 & 23.5 \\ 47 & 39.9 & 15.7 & 41.4 & 3.0\end{array}$

Men normals

$\begin{array}{rrrrr}29 & 9.0 & 29.4 & 30.9 & 30.6 \\ 19 & 14.9 & 66.1 & 13.3 & 5.6 \\ 50 & 22.0 & 38.1 & 32.5 & 7.4 \\ 50 & 29.5 & 42.8 & 26.0 & 1.6 \\ 36 & 32.5 & 27.2 & 27.9 & 12.5 \\ 29 & 31.5 & 32.5 & 29.6 & 6.5 \\ 33 & 16.7 & 30.8 & 46.5 & 6.0 \\ 22 & 9.6 & 24.0 & 40.1 & 26.3 \\ 40 & 27.0 & 42.3 & 25.4 & 5.3\end{array}$

Women patients

$\begin{array}{crrrr}79 & 6.4 & 10.2 & 76.7 & 6.7 \\ 39 & 65.6 & 16.5 & 17.2 & 0.7 \\ 39 & 10.3 & 45.4 & 37.5 & 6.7 \\ 16 & 21.2 & 36.7 & 32.9 & 9.1 \\ 37 & 17.2 & 21.1 & 47.3 & 14.5 \\ 36 & 15.8 & 29.3 & 35.1 & 19.8 \\ 50 & 16.8 & 24.6 & 25.1 & 33.5 \\ \text { Women normals } & & & & \\ 33 & 18.5 & 54.5 & 17.9 & 9.1 \\ 24 & 20.8 & 27.7 & 49.8 & 1.8 \\ 26 & 34.8 & 35.0 & 26.7 & 3.5 \\ 28 & 15.9 & 48.2 & 33.5 & 2.3 \\ 30 & 1.9 & 22.3 & 75.8 & 0 \\ 26 & 24.0 & 31.0 & 45.0 & 0 \\ 26 & 16.0 & 45.3 & 29.3 & 9.3 \\ 27 & 21.3 & 48.4 & 26.3 & 4.0 \\ 33 & 35.2 & 35.5 & 26.2 & 3.1 \\ 19 & 30.4 & 20.7 & 32.9 & 16.0 \\ 35 & 11.4 & 30.8 & 51.9 & 6.0 \\ \end{array}$

All values are percentage of total inhibitory activity eluted in one of four DEAE column chromatography fractions; the four fractions are each defined by the conductivity (in millisiemens per centimeter) at the start and end of the fraction: A, 12-22; B, 23-29; C, 30-39; and $D, 40-45$. Ages are in years. ionic strength fractions of GCI separately, and labeled them A, B, C, and $D$ in order of ascending ionic strength of elution (Table I). Fractions were collected even if there was no peak.

Each inhibitor fraction (A-D) from patients and normals was further purified. To remove adsorbed pigments, each fraction was chromatographed on a Bio-Gel P-10 column in a 50\% formamide aqueous solution. The formamide was removed by dialysis, and the solution lyophylized (12). The lyophilized material was taken up in $0.05 \mathrm{M}$ Tris-HCl- $0.2 \mathrm{M}$ $\mathrm{NaCl}$ (pH 7.3) and applied to a $2 \times 110-\mathrm{cm}$ Sephacryl S-200 column (12). The inhibitory material from each fraction eluted in a single peak that was collected for further study. Each of the four fractions from normals and from patients were combined to provide normal and patient A, B, C, and D pools; each of the resulting eight pooled samples (patients A-D and normals A-D) contained enough protein that all of the physical and chemical characterization studies could be performed on each peak.

\section{Inhibition assay}

Measurement of crystal growth rate. The inhibitory activity of purified proteins was measured using a seeded crystal growth system detailed previously $(1,11)$. The assay solution contained $5 \mathrm{ml}$ of $2 \times 10^{-3} \mathrm{M}$ $\mathrm{CaCl}_{2}$ in $0.05 \mathrm{M}$ sodium barbiturate-sodium acetate buffer ( $\mathrm{pH} 5.7$ ), $0.133 \mathrm{M} \mathrm{NaCl}, 1 \mathrm{ml}$ of calcium oxalate monohydrate seed crystal slurry $(1.5 \mathrm{mg} / \mathrm{ml})$, and variable amounts of protein in the range of $10^{-6}-10^{-8}$ $\mathrm{M}$, usually in $200 \mu \mathrm{l}$ of buffer. The assay was initiated by adding $5 \mathrm{ml}$ of $0.4 \times 10^{-3} \mathrm{M}$ sodium oxalate with $\left[{ }^{14} \mathrm{C}\right]$ sodium oxalate as a tracer in $0.05 \mathrm{M}$ sodium barbiturate-sodium acetate buffer with $0.133 \mathrm{M} \mathrm{NaCl}$ (pH 5.7), after the temperature was equilibrated to $37^{\circ} \mathrm{C}$. The loss of calcium or oxalate from the solution into the crystals follows a second order rate law $(1,2,10)$ :

$\mathrm{dC}_{\mathrm{t}} / \mathrm{d} t=k\left(\mathrm{C}_{\mathrm{t}}-\mathrm{C}_{\mathrm{e}}\right)^{2}$,

where $C_{t}$ is the concentration of calcium or oxalate at any time, $t<t_{e}$, $t_{\mathrm{e}}$ is the time required for the solution and crystals to come to thermodynamic equilibrium, $\mathrm{C}_{\mathrm{e}}$ is $\mathrm{C}_{t}$ at $t=t_{\mathrm{e}}$, and $k$ is the empirical rate constant. The integrated form is:

$\mathrm{C}_{t}=\left(\mathrm{C}_{\mathrm{i}}+a \mathrm{C}_{\mathrm{e}} t\right) /(1+\mathrm{at})$, where $a=k\left(\mathrm{C}_{\mathrm{i}}-\mathrm{C}_{\mathrm{e}}\right)$, and $\mathrm{C}_{\mathrm{i}}$ is $\mathrm{C}_{t}$ at $t=0$.

At intervals of incubation from $10 \mathrm{~s}$ to $24 \mathrm{~h}$, aliquots were withdrawn and filtered (Metricel Ga-8, pore size $0.2 \mu \mathrm{m}$ ), and the filtrate radioactivity determined by liquid scintillation counting (Beckman liquid scintillation counter, LS-230). The time course data for $\left[{ }^{14} \mathrm{C}\right]$ oxalate were fitted by nonlinear regression to Eq. 2, to derive values of $\mathrm{C}_{i}, \mathrm{C}_{e}$, and $k$ that give a best fit of $\mathrm{C}_{t}$ to $t$ for selected concentrations of pooled A-D protein from normals and patients, and for control tubes containing no added protein. Measured values of $C_{e}$ at $24 \mathrm{~h}$ were within $5 \%$ of those estimated by the regression, and of that calculated from the solubility product for calcium oxalate monohydrate crystals in our system $(1,10,11)$.

Adsorption coefficients. The interaction of GCI molecules and the calcium oxalate crystal surface was treated in the most simple manner, by assuming that the crystals possess sites with which GCI molecules can interact reversibly so that the number of sites bound to $\mathrm{GCI},[\mathrm{X}]$, is proportional to the product of free sites, [S], and inhibitor concentration at the surface, [I]. [I] is assumed to equal the solution concentration of inhibitor protein:

$Z=[\mathrm{I}][\mathrm{S}] /[\mathrm{X}]$, where $Z$ is an association constant of $\mathrm{I}$ with $\mathrm{S}$.

This model can be made useful given two additional statements that are not new assumptions, but rather definitions:

$k_{\mathrm{e}}=w[\mathrm{~S}]$, where $k_{\mathrm{e}}$ is a value of $k$ in the presence of inhibitor;

$k_{0}=w([\mathrm{~S}]+[\mathrm{X}])$, where $k_{0}$ is the value of $k$ with no inhibitor present.

$w$ is a proportionality constant that is removed by combining Eqs. 3-5; 
$[\mathrm{I}]=\mathrm{Z}\left(k_{0}-k_{\mathrm{e}}\right) / k_{\mathrm{e}}$; this is the Langmuir type isotherm (11).

Values of $Z$ were calculated by nonlinear fitting of values of measured $k_{\mathrm{e}}$ at various values of [I] to derive those values of $Z$ and $k_{0}$ that give the best fit of [I] to $k_{\mathrm{e}}$. In all cases, estimated values of $k_{0}$ were within $5 \%$ of measured values in tubes having no added protein. The fit of $\left(k_{0}-k_{\mathrm{e}}\right) /$ $k_{\mathrm{e}}$ to [I] could not be improved by addition of higher order terms, as judged by stepwise polynomial curve fitting using final best fit values for $Z$ and $k_{0}$. All values of $Z$ differed significantly from zero.

Inhibition by chromatographic eluates. During purification, we used a combination of Eqs. 2 and 6 to give a simplified approximation of inhibition (1) that could be used for multiple chromatographic samples:

$k=\left(\mathrm{C}_{\mathrm{i}}-\mathrm{C}_{t}\right) /\left[\left(\mathrm{C}_{t}-\mathrm{C}_{\mathrm{e}}\right)\left(\mathrm{C}_{\mathrm{i}}-\mathrm{C}_{\mathrm{e}}\right) t\right]$, from Eq. 2 ;

if $C_{t}$ is called $C_{z}$ when inhibitor is present and $C_{0}$ when no inhibitor is present, Eq. 7 can be substituted for the values of $k_{0}$ and $k_{\mathrm{e}}$ in Eq. 6:

$[I] / Z=\left[\left(C_{z}-C_{0}\right)\left(C_{i}-C_{e}\right)\right] /\left[\left(C_{i}-C_{z}\right)\left(C_{0}-C_{e}\right)\right]$.

We measured $C_{0}$ once in each assay of 25-72 samples, took $C_{i}$ to be the starting $\left[{ }^{14} \mathrm{C}\right]$ oxalate concentration of the solution, $\mathrm{C}_{\mathrm{e}}$ to be the value in the control tubes at $24 \mathrm{~h}$. We made all measurements of $C_{t}$ at $40 \mathrm{~min}$ for all samples, from which values of $[\mathrm{I}] / Z$ could be calculated and used as an index of how much of a given inhibitor was present in each, if $Z$ were assumed to be constant.

Distribution of $A, B, C$, and $D$ inhibitors. Since a separate DEAEcellulose chromatography elution was performed for each subject, inhibitor content in each of the four regions (A-D) could be calculated for Eq. 8 for each tube and each region; we then plotted for each tube of eluate the inhibition against the ionic conductivity in that tube. The inhibitor assay result in each tube was divided by the total of the assay results for all of the tubes from the chromatogram, to give a percentage, and the total percentage of inhibition was calculated for each of the four fractions (A-D) for each urine sample (Table I). The mean percentage for each of the four fractions was then calculated for the normals and patients using the values in Table I (Fig. 1). The mean percentages of total inhibitor in the $A$ and $C$ fractions were the same for patients and normals. However, normal urine contained more $B$ and less $D$ inhibitor than urine from patients. Direct quantitative comparisons between individuals, or even fractions, cannot be derived from this simplified expression, as complete kinetic data are approximated by a single 40 min measurement, and both [I] and $Z$ are unknowns. We estimated the individual variability of the A-D fraction proportions in one patient and two normals. In 11 samples, the male normal had $22 \pm 4,52 \pm 6,17 \pm 4$, and $9 \pm 2$ for $\% A-D( \pm S E M)$, respectively; corresponding percentage values for 11 replicates for the woman normal were $16 \pm 3,36 \pm 6,35 \pm 5$, and $13 \pm 3$; for the male patient, values for eight replicates were $17 \pm 4$, $18 \pm 3,39 \pm 7$, and $27 \pm 6$. Coefficients of variation for A-D, respectively, were (in percentage) $62,36,68$, and 74 for the male normal, 64, 53, 49, and 79 for the woman normal, and 63,36, 49, and 67 for the patient.

Surface property measurements. The surface pressures of the purified

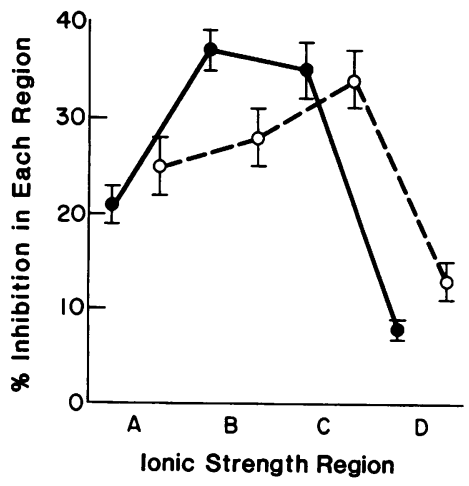

Figure 1. Distribution of AD GCI molecules in patients (o) and normal subjects (๑). Values are means \pm SEM. A-D refer to the ionic strength at which inhibitory molecules elute from DEAE-cellulose (see legend to Table I and Methods). Ordinate shows the percentage of total calcium oxalate crystal growth inhibition within each of the four fractions. Normal percentage B exceeds patients, $P<0.01$; patient percentage $\mathrm{D}$ exceeds normals, $P<0.01$. human urinary inhibitors at the air-water interface were investigated using a Lauda film balance. A, B, C, or D pooled inhibitor from patients or normals was dissolved in $0.01 \mathrm{M}$ Tris- $0.1 \mathrm{M} \mathrm{NaCl}(\mathrm{pH} \mathrm{7.4)}$ and dialyzed against 1 liter of the same buffer. Collapse pressure of an inhibitor was measured by spreading $130 \mu \mathrm{g}$ of protein over the same buffer solution in the tank of a Lauda film balance, and reversibly compressing and expanding the surface film between 600 and $20 \mathrm{~cm}^{2}$ at a rate of $2.2 \mathrm{~cm}^{2} /$ s (11). All experiments were carried out at $22^{\circ} \mathrm{C}$. Buffers were easily contaminated with surfactants such as oils and detergents that are normally undetectable and of no consequence, but which can drastically alter force area curves. To remove contaminating surfactants, all buffers used to dissolve and dialyze the inhibitor proteins were aerated by a stream of fine bubbles, on whose surfaces contaminants adsorbed, floated to the buffer-air interface, and were removed by discarding the surface portion of the solution.

\section{Other methods}

Materials. DEAE-Cellulose (Whatman DE-52) was recycled using 0.5 $\mathrm{N} \mathrm{HCl}$ and $0.5 \mathrm{~N} \mathrm{NaOH}$ before equilibration with $0.05 \mathrm{M}$ Tris- $\mathrm{HCl}-$ $0.05 \mathrm{M} \mathrm{NaCl}$ (pH 7.3). Tris-(hydroxymethyl)aminomethane (Trizma base) was obtained from Sigma Chemical Co., St. Louis, MO, and $\mathrm{U}\left[{ }^{14} \mathrm{C}\right]$ oxalic acid, $75 \mathrm{Ci} / \mathrm{mol}$, was purchased from Amersham Corp., Arlington Heights, IL. Seed crystals of calcium oxalate monohydrate and the dialysis tubing (molecular weight cut-off, 8,000, Spectra/Por I, Spectrum Medical Industries, Inc., Los Angeles, CA) were prepared as described previously (11). $\gamma$-Carboxyglutamic acid (Gla) monoammonium salt was obtained from Calbiochem-Behring Corp., La Jolla, CA. All chemicals were the highest grade available and were not purified further. Water was distilled in an all-glass apparatus after passing through a mixed resin deionizer.

Protein determination. Protein concentration in the urine specimen was determined by trichloroacetic acid precipitation followed by the Lowry method with phenol reagent (19). An aliquot of $0.5-\mathrm{ml}$ sample was mixed with an equal amount of $20 \%$ trichloroacetic acid aqueous solution and heated in a boiling water bath for $10 \mathrm{~min}$, then centrifuged to collect denatured protein. The precipitated protein was dissolved in $2 \mathrm{ml}$ of Lowry reagent, and after $10 \mathrm{~min}, 0.2 \mathrm{ml}$ of phenol reagent was added; protein concentration was determined at $750 \mathrm{~nm}$ after $30 \mathrm{~min}$. When the inhibitor was further purified, the protein concentration was determined by alkaline hydrolysis followed by ninhydrin color reaction for determining absorbance at $570 \mathrm{~nm}$ (20). In both cases, calibration standards were prepared using bovine serum albumin from 10 to $75 \mu \mathrm{g}$. Elution of protein during column chromatography was monitored by absorption at 280 or $230 \mathrm{~nm}$. The salt gradient used in DEAE-cellulose column chromatography was monitored using a conductivity meter (model CDM 83, Radiometer, Copenhagen, Denmark).

Carbohydrate analysis. Carbohydrate content was analyzed by gas chromatography (Perkin-Elmer, model 910, with 3\% OV-1 Superlcoport column, $14^{\prime \prime}$ (i.d.) and $12^{\prime}$ length glass tubing, and flame ionization detector). Materials were hydrolyzed in $1 \mathrm{~N} \mathrm{HCl}$-methanol at $80^{\circ} \mathrm{C}$ for 24 h, acetylated, and trimethylsilylated as described by Clamp et al. (21). Peak areas were measured by electronic integration (Sigma 10 analyzer, Perkin-Elmer Corp.). Mannitol was used as the internal standard. The retention time and response factor for each monosaccharide were established using fucose, glucose, galactose, mannose, glucosamine, galactosamine, mannosamine, glucuronic acid, and $N$-acetylneuraminic acid.

Amino acid analysis. Amino acid analysis was carried out using a $118 \mathrm{Cl}$ analyzer (Beckman Instruments Inc., Palo Alto, CA) with W-3P resin and lithium citrate buffer after hydrolysis in evacuated-sealed tubes containing $6 \mathrm{~N} \mathrm{HCl}$, at $110^{\circ} \mathrm{C}$, for $24 \mathrm{~h}$. The number of Gla residues was determined after $24 \mathrm{~h}$ alkaline hydrolysis as described by Hauschka (22). Elution position and color factor were determined using standard Gla. Using bovine blood coagulation Factor IX (Sigma Chemical Co.) as a known Gla-containing protein, we found 11 residues of Gla per molecule, and a ratio of 0.273 of Gla to glutamic acid residues. This compares favorably with reported values of 12 residues per mole (23) and a ratio of $0.297 \pm 0.007$ (24). Tryptophan was determined spectrophotometrically after the method of Beaven and Holiday (25). 
Molecular weight determination. Molecular weight was determined by Sephacryl S-200 column chromatography $(2 \times 110 \mathrm{~cm})$ and high performance liquid gel permeation chromatography (HPLC) (HPLC model 110A, Beckman Instruments Inc.) using a Toyo-Soda column, TSK-G3000W $(1.5 \times 600 \mathrm{~mm})$ with $0.05 \mathrm{M}$ Tris- $\mathrm{HCl}-0.1 \mathrm{M} \mathrm{NaCl}$ containing $0.02 \%$ sodium azide ( $\mathrm{pH} 7.5$ ) as a solvent. The calibration curve was established using bovine serum albumin $(68,000 \mathrm{~mol} \mathrm{wt})$, ovalbumin (43,000 mol wt), Kunitz soybean trypsin inhibitor ( $21,000 \mathrm{~mol} \mathrm{wt})$, and bovine pancreatic ribonuclease $(13,700 \mathrm{~mol} \mathrm{wt})$. All of the eight inhibitors, patient and normal, A-D, eluted from the Sephacryl column at a $\mathrm{K}_{\text {everae }}$ of $0.58-0.59$, virtually identical to the position of the ribonuclease, 0.585 , and indicating a molecular weight of 14,000 . Their retention times by high performance liquid chromatography were all 7.8-8 min, indistinguishable from that of ribonuclease, which was $7.8 \mathrm{~min}$, and indicated the same molecular weight $(14,000)$. This is the same molecular weight we have established for the normal B inhibitor in our previous study (12).

Statistical methods. Linear and nonlinear regressions, and tests of significance of differences between groups were performed using standard methods for digital computer (BMDP, UCLA School of Computer Sciences, Los Angeles, CA).

\section{Results}

Dissociation constants. Patient and normal inhibitors differed in their dissociation constants as derived from the slopes of the Langmuir isotherm type plots (Fig. 2). Normal A-D inhibitors all had approximately the same constants, between 1.7 and $5 \times 10^{-7} \mathrm{M}$. Patient inhibitors A and B had constants in this range, and both constants were lower than those of corresponding normal materials (Fig. 2). However, the $C$ and $D$ inhibitors from patients had higher values (lower affinities for the crystals) than corresponding normal materials (Fig. 2). The Langmuir isotherm graphs were linear for all materials (Fig. 3, A-D), and all slopes differed significantly from zero (see legend to Fig. 2). Since the C and D inhibitors together constituted $46 \%$ of the total for patient material (Fig. 1), about half of the inhibitor from patients was of subnormal affinity, i.e., less inhibitory on a molar basis than normal.

Surface properties. The collapse pressures of patient inhibitors A-C were below corresponding normal values (Fig. 4, A-C); the $D$ inhibitors of normals and patients were the same. In addition, the area occupied by patient $\mathrm{A}, \mathrm{B}$, and $\mathrm{C}$ inhibitors was much

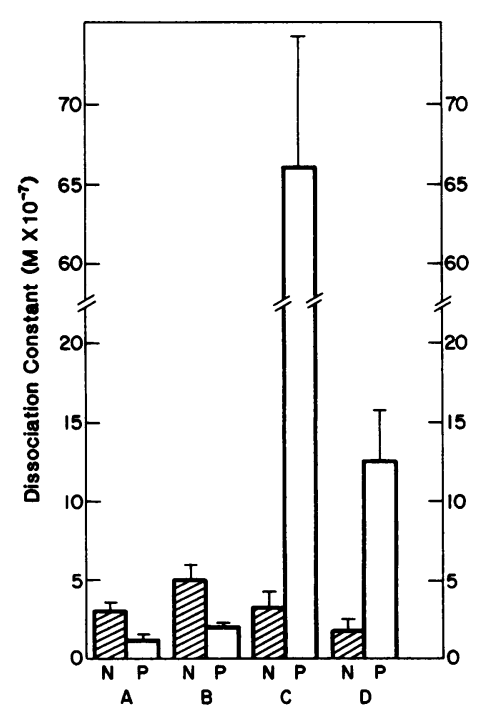

Figure 2. Langmuir adsorption coefficients. Values \pm SEM for normals $(\mathrm{N}$ crosshatch) and patients ( $P$, open bars) for the A-D fractions depicted in Fig. 1. Ordinate shows the slopes of langmuir type isotherm regressions (Methods) depicted in Fig. $3 \mathrm{~A}-\mathrm{D}$. Patients and normals differed, $P<0.01$ for $\mathrm{A}$ and $\mathrm{B}$, and $P<0.001$ for $\mathrm{C}$ and $\mathrm{D}$. (Note changed scale indicated by broken ordinate line.) lower than corresponding normal materials at all values of surface force, so that the patient curves were shifted to the left of the normal curves. The patient $\mathrm{D}$ curve was not displaced to the left, but slightly to the right.

\section{Chemical composition}

Amino acids. Normal A-C inhibitors contained Gla, but none could be detected in normal $\mathrm{D}$ or in any of the patient inhibitor fractions (Table II). All other amino acids were present in similar proportions, within $8 \%$, in all four fractions of patient and normal inhibitors. As we have reported in the past (11-13), the inhibitors are enriched in aspartic and glutamic acids, and contain few basic (lysine and arginine) and aromatic (tyrosine, phenylalanine, and tryptophan) residues.

Carbohydrates. The inhibitors were from 3.5 to $10.3 \%$ carbohydrate (Table III), and all contained fucose, galactose, mannose, glucose, galactosamine, glucosamine, and $N$-acetylneuraminic acid, but no glucuronic acid. There were no systematic differences between normal and patient materials.

\section{Discussion}

Patients who form calcium oxalate stones seem to produce urinary GCI molecules that inhibit calcium oxalate crystal growth less than normal material. The affinities of the $C$ and $D$ fractions of patient inhibitor for the calcium oxalate crystal are below corresponding normals by $>20$-fold and fourfold, respectively, and the $C$ and $D$ fractions account for $46 \%$ of the total inhibitor in patient samples. A lesser degree of kinetic crystal growth inhibition at any given concentration means that if patients excrete as much inhibitor as normals they will have less total effective inhibition of crystal growth, and therefore a greater potential for forming stones. We (1) and others $(3,5,9,14)$ have found less overall inhibition of calcium oxalate crystal growth by urine from stone formers compared with normal; part of this deficit may be due to the intrinsic molecular disorder we describe here.

We divided GCI into four fractions because up to four peaks of inhibition could be eluted from a DEAE-cellulose column; the fractions were chosen to correspond to the positions of the four peaks. The elution of inhibitory molecules from a DEAEcellulose column over a wide range of ionic strengths suggests that GCI may have different molecular forms, and for this reason we refer to $\mathrm{GCI}$ molecules throughout this report. One alternative is that the four forms differ in their primary amino acid sequence. Another is that they are all the same peptide, but differ in carbohydrate composition enough to cause heterogeneity of ionic association with the DEAE-cellulose. Differences in Gla could account for a separate $D$ peak in normal $G C I$, as normal $D$ has no Gla, whereas A to C GCI each contain 2-3 Gla residues. However, none of the patient materials contain Gla, yet they elute in A-D peaks that overlap with those of the normal GCI. The elution position from DEAE-cellulose is strongly related to crystal surface affinity in patient, but not normal samples. Overall, the reasons for the heterogeneity, and its relationship to function remain to be explored. Also unexplored is the interaction between the four forms. They may act synergistically, or they may combine to form large molecules that are more inhibitory; these are untested possibilities.

Patient inhibitors formed surface films at the air-water interface that were less stable than normal. In general, stable films are formed by molecules that are amphiphilic: they have regions that are strongly hydrophilic - that will tend to remain in 

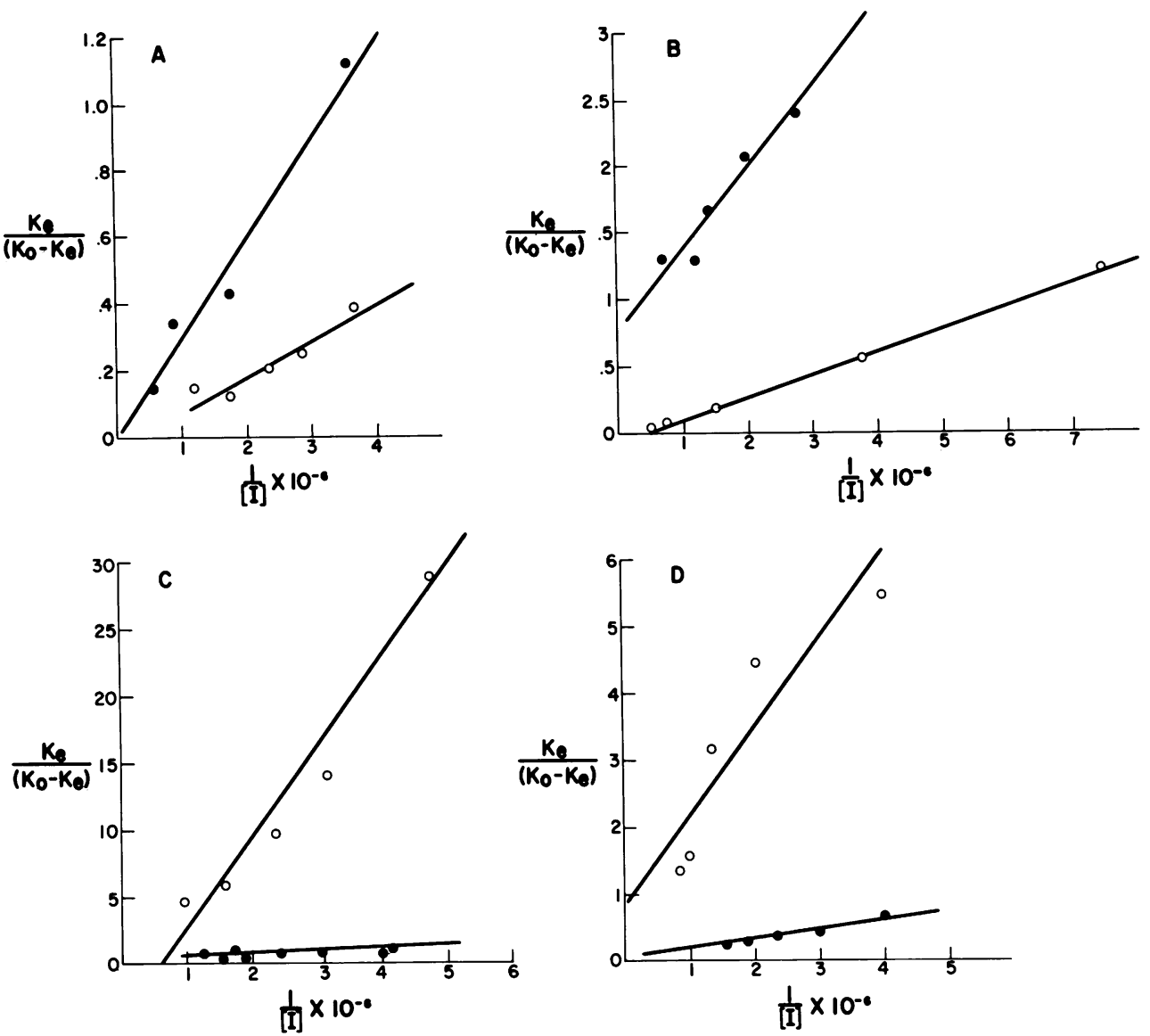

Figure 3. Langmuir adsorption isotherm type plots showing effect of A-D inhibitors from patients (O) and normals $(\bullet)$ on calcium oxalate crystal growth. $k_{e}$ and $k_{0}$ refer to the kinetic growth rate constant of crystals with and without added inhibitor, respectively. [I] is molar concentration of purified $\mathrm{GCI}$ from fractions $A(3 A), B(3 B), C(3 C)$, and $D(3 D)$. Values of slopes, which give the affinities of GCI for the crystal surface, are shown in Fig. 2. Intercepts for patient and normal A-D, respectively: -0.31 vs. $-0.072 ; 0.654$ vs. $0.55 ;-1.03$ vs. -40.6 ; and -0.198 vs. -8.74 . Regression lines are best fit to linear functions; by polynomial regression, higher order regression terms did not improve the fit of the regression to the data. All regressions were significant $P<0.001$. aqueous solution-and other regions that are hydrophobic, and will resist entering the solution (26). Presumably, the reduced film stability of patient material reflects a loss of well separated hydrophobic and hydrophilic groups. The biological meaning of the normal surfactant quality of $\mathrm{GCI}$, and its attenuation in patients with stones, is unknown. Perhaps strong film forming proteins coat the crystals and prevent solution ions from reaching the surface.

The patient inhibitors also were abnormal in containing no Gla, an amino acid that is present in normal A, B, and C material. Gla possesses two carboxyl groups at one end, and occurs in blood-clotting proteins (27), and in a protein found in bone (28). The Gla molecules can bind calcium (29), and appear essential for the biological activity of prothrombin (30). Their function in GCI is unknown; however, one hypothesis is that they play some role in maintaining the conformation of the molecule. The normal type B inhibitor has an axial ratio of 6:1 (12), and has a highly organized two-dimensional structure with strong amphiphilic properties that would stabilize it at the air-water interface. The Gla residues could control the conformation of the GCI molecule through calcium binding; aggregation of troponin A (31) and formation of the hydrophobic properties of calmodulin (32) both occur with calcium binding. If Gla residues do stabilize the two-dimensional structure of urine GCI, perhaps through shared binding of calcium ions, and if such stabilization separates strongly hydrophobic and hydrophilic regions, the abnormal molecules may have less marked surfactant properties than normal because they lack Gla. Our data strongly support this hypothesis. Collapse pressures of normal A, B, and C GCI, which contain Gla, exceed values for the corresponding materials from patients, which lack Gla. The normal D material, which lacks Gla, has the same collapse pressure as patient D; and both lack Gla. Normal D has the lowest collapse pressure of the four normal GCI molecules. Clearly, this issue can only be resolved by studies beyond the present one, such as deliberate decarboxylation of A or B GCI.

Our finding of no Gla in patient inhibitors contrasts with the study of Lian et al. (33), who isolated from renal calculi a protein that contains Gla and resembles the ones we describe here. Calcium, but not uric acid stones, contain proteins rich in aspartic and glutamic acids, low in lysine and arginine, and possessing Gla. One of them, of $17,000 \mathrm{~mol} \mathrm{wt}$, contained 39 residues of Gla per 1,000 amino acids, and 290 and 188 of aspartic and glutamic acids, respectively, per 1,000 amino acid residues; this protein may be very similar to ours.

Why did they find Gla rich proteins in stones, while we found no Gla in our inhibitors? One hypothesis, which we favor, is that stones naturally accumulate and concentrate inhibitors from urine-because the inhibitors stick to the calcium oxalate crystals-so stones become very concentrated with inhibitors. The enrichment allows one to detect Gla proteins that are so subnormal in amount that our methods, based upon urine alone, fail to disclose them. Since the normal inhibitors have Gla, and higher affinity for the calcium oxalate surface, it may be that the Gla proteins that patients do produce are selectively trapped on the stones, so they can be recovered from stones even though they are present in such small amounts in urine as to escape notice. Testing of this notion will require comparison of stone inhibitors to those isolated from urine.

Kidney stone proteins that seem superficially like ours have 

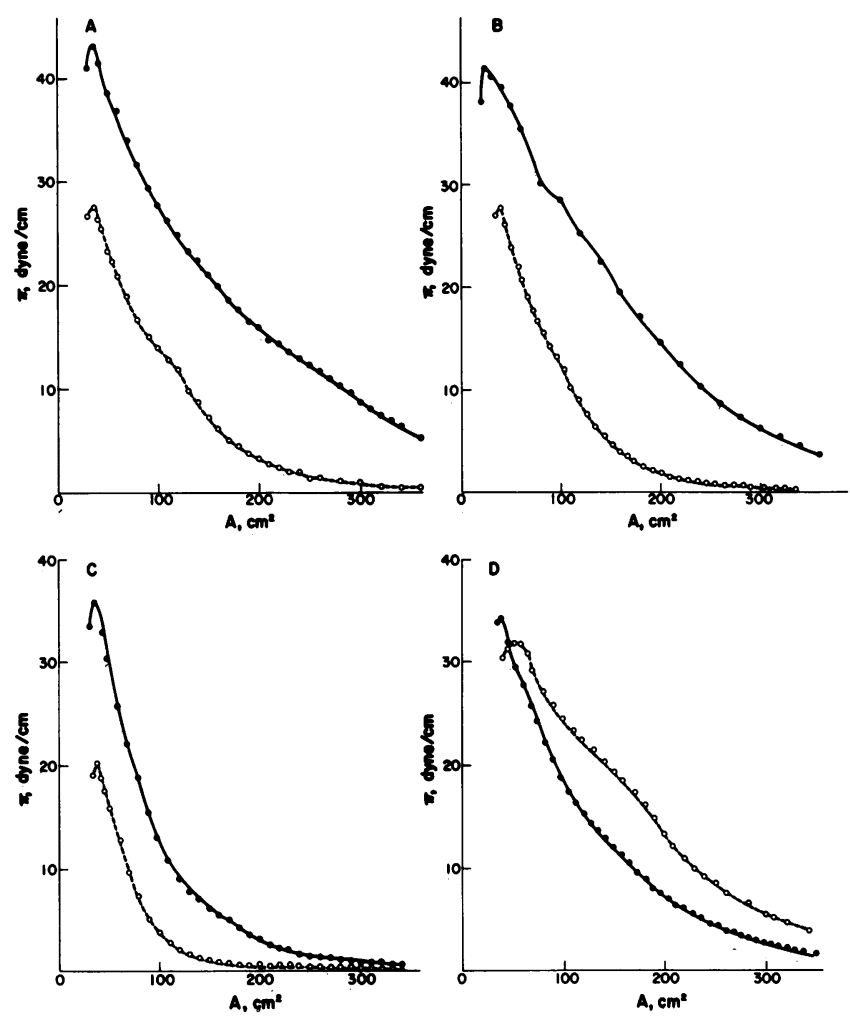

Figure 4. Force area curves for A-D inhibitors (Figs. 4 A-D, respectively) from normals $(\bullet)$ and patients $(0)$. Surface films of $135 \mu \mathrm{g}$ protein were compressed and expanded between 600 and $20 \mathrm{~cm}^{2}$ at 2.2 $\mathrm{cm}^{2} / \mathrm{s}$. Collapse pressures (dyne per centimeter) of normal A-C exceeded corresponding values for patient materials: 33.2 vs. $27.8,41.4$ vs. 27.6 , and 36 vs. 20.4 ; values for $D$ were nearly the same: 34.2 vs. 32. also been detected by others than Lian et al. (34-36), who describe proteins from stones rich in aspartic and glutamic acids. Direct comparisons of the proteins described previously to the ones described here should be made with caution, as our purification scheme involves removal of contaminating pigments, and both ionic exchange and molecular sieving as separation procedures, whereas Lian et al. (33) used only molecular sieving. Furthermore, we separated materials using an inhibition assay and direct monitoring of protein concentration, whereas others (33-36) have followed optical density peaks.

Despite their abnormal behavior and composition, patient inhibitors were much like normal ones in amino acid and carbohydrate composition and molecular weight. All of the inhibitors from patients and normals had a high percentage of acidic amino acids, few basic and aromatic amino acid residues, and similar sugars. They are also similar to inhibitor molecules we have purified from cell culture medium (11) and rat kidney tissue and urine (13), suggesting that these proteins have been reasonably stable during evolution.

Our study used pooled materials rather than proteins isolated from individuals, and so our results refer to the average behavior and composition of normal and patient inhibitors. For example, the dissociation constants of $\mathrm{C}$ and $\mathrm{D}$ proteins from some patients may be normal, and the constants of proteins from other patients far more abnormal than the average value we studied. Analogous variability may be present in their interfacial film-forming behavior. In other words, our design precludes statements about heterogeneity among subjects. For Gla contents, this limitation may not be very important, as no patient protein contained the amino acid.

Overall, the present study suggests that a molecular disorder may be responsible for some component of calcium oxalate nephrolithiasis, but the actual basis for the functional disorders

Table II. Amino Acid Compositions of Inhibitors

\begin{tabular}{|c|c|c|c|c|c|c|c|c|}
\hline & \multicolumn{2}{|l|}{ A } & \multicolumn{2}{|l|}{ B } & \multicolumn{2}{|l|}{ c } & \multicolumn{2}{|l|}{ D } \\
\hline & $\mathbf{N}$ & $\mathbf{P}$ & $\mathbf{N}$ & $\mathbf{P}$ & $\mathbf{N}$ & $\mathbf{P}$ & $\mathbf{N}$ & $\mathbf{P}$ \\
\hline Lysine & 2.5 & 1.6 & 2.4 & 1.7 & 2.8 & 2.3 & 2.0 & 2.0 \\
\hline Histidine & 2.0 & 1.4 & 1.0 & 2.0 & 1.8 & 2.4 & 2.5 & 2.5 \\
\hline Arginine & 2.4 & 2.2 & 1.6 & 2.6 & 2.8 & 2.4 & 2.3 & 2.3 \\
\hline Aspartic acid & 12.9 & 14.2 & 13.2 & 11.8 & 11.4 & 12.1 & 11.2 & 11.2 \\
\hline Threonine & 13.9 & 11.5 & 8.4 & 8.0 & 9.5 & 10.0 & 11.5 & 12.0 \\
\hline Serine & 9.8 & 9.8 & 10.6 & 8.8 & 10.0 & 11.0 & 11.4 & 11.4 \\
\hline Glutamic acid & 13.2 & 13.1 & 13.4 & 14.4 & 12.6 & 13.3 & 12.2 & 12.2 \\
\hline Proline & 8.8 & 7.5 & 6.7 & 7.2 & 7.5 & 9.0 & 7.2 & 7.2 \\
\hline Glycine & 9.5 & 10.5 & 9.2 & 11.8 & 10.0 & 12.2 & 11.0 & 11.0 \\
\hline Alanine & 9.2 & 7.9 & 9.4 & 6.4 & 9.0 & 9.7 & 9.7 & 8.7 \\
\hline 1/2 Cystine & 2.0 & 1.8 & 1.9 & 1.3 & 1.6 & 1.7 & 2.4 & 2.4 \\
\hline Valine & 7.2 & 7.5 & 7.6 & 6.4 & 6.8 & 7.8 & 8.9 & 7.9 \\
\hline Methionine & 1.4 & 0.6 & 0.7 & 0.5 & 0.6 & 0.8 & 1.3 & 1.3 \\
\hline Isoleucine & 3.0 & 3.3 & 2.0 & 2.2 & 2.5 & 3.1 & 3.0 & 3.0 \\
\hline Leucine & 9.9 & 7.5 & 7.5 & 5.2 & 7.6 & 9.3 & 7.7 & 6.7 \\
\hline Tyrosine & 1.7 & 1.2 & 1.0 & 1.0 & 1.8 & 2.8 & 2.7 & 3.5 \\
\hline Phenylalanine & 4.0 & 3.4 & 2.6 & 2.8 & 2.4 & 2.5 & 3.5 & 3.5 \\
\hline Tryptophan & 1.4 & ND & 1.1 & ND & 0.9 & ND & 1.2 & ND \\
\hline$\gamma$-Carboxyglutamic acid & 3.4 & 0 & 2.1 & 0 & 2.0 & 0 & 0 & 0 \\
\hline
\end{tabular}

A-D refer to fractions eluted from DEAE-cellulose; see Methods and legend to Table I and Fig. 1. N, normal subjects; P, patients; ND, not determined. All values are residues per molecule of GCI. 
Table III. Carbohydrate Compositions of Urine GCI Molecules

\begin{tabular}{|c|c|c|c|c|c|c|c|c|}
\hline \multirow[b]{2}{*}{ Carbohydrate } & \multicolumn{2}{|l|}{ A } & \multicolumn{2}{|l|}{ B } & \multicolumn{2}{|l|}{$\mathrm{C}$} & \multicolumn{2}{|l|}{ D } \\
\hline & $\mathbf{N}$ & $\mathbf{P}$ & $\mathbf{N}$ & $\mathbf{P}$ & $\mathbf{N}$ & $\mathbf{P}$ & $\mathbf{N}$ & $\mathbf{P}$ \\
\hline Fucose & 0.3 & 0.3 & 0.3 & 0.1 & 0.3 & 0.1 & 0.1 & 0.4 \\
\hline Galactose & 3.2 & 3.2 & 2.5 & 3.7 & 2.2 & 1.3 & 3.7 & 0.7 \\
\hline Mannose & 0.8 & 0.9 & 1.2 & 0.2 & 1.1 & 0.4 & 0.2 & 0.6 \\
\hline Glucose & 0.6 & 0.6 & 1.2 & 0.3 & 0.1 & 0.2 & 0.3 & 0.9 \\
\hline Galactosamine & 0.8 & 0.8 & 1.5 & 2.7 & 0.8 & 1.4 & 2.7 & 1.2 \\
\hline Glucosamine & 0.4 & 0.4 & 1.0 & 0.4 & 0.8 & 0.1 & 0.4 & 1.2 \\
\hline$N$-Acetylneuraminic acid & + & + & + & + & + & + & + & + \\
\hline Total & 6.1 & 6.2 & 10.3 & 7.4 & 5.3 & 3.5 & 7.7 & 5.0 \\
\hline
\end{tabular}

A-D refer to fractions eluted from DEAE-cellulose; see Methods and legend to Table I. N, normal subjects; P, patients. All values are weight percentage.

in the patient inhibitors is totally unknown. Patient GCI molecules have lower crystal affinity, no detectable Gla, and weak surfactant properties compared with normal; the relationship of Gla to surface properties, and of surface properties to crystal surface affinity and overall effectiveness as an inhibitor are unknown.

\section{Acknowledgments}

We wish to thank Professors F. J. Kézdy and E. T. Kaiser for their valuable suggestions and discussions. We thank also Mrs. Siok Le Dun for her assistance at the initial stage of this work.

This research was supported by U. S. Public Health Service grants IP50 AM 20585 and AM 33949.

\section{References}

1. Coe, F. L., H. C. Margolis, L. H. Deutsch, and A. L. Strauss. 1980. Urinary macromolecular crystal growth inhibitors in calcium nephrolithiasis. Miner. Electrolyte Metab. 3:268-275.

2. Meyer, J. L., and L. H. Smith. 1975. Growth of calcium oxalate crystals. II. Inhibition by natural urinary crystal growth inhibitors. Invest. Urol. 13:36-39.

3. Robertson, W. G., and M. Peacock. 1972. Calcium oxalate crystalluria and inhibitors of crystallization in recurrent renal stone-formers. Clin. Sci. 43:499-506.

4. Smith, L. H., J. L. Meyer, and J. T. McCall. 1972. Chemical nature of crystal inhibitors isolated from human urine. Int. Symp. Renal Stone Res., Madrid. 318-327.

5. Dent, C. E., and D. J. Sutor. 1971. Presence or absence of inhibitor of calcium-oxalate crystal growth in urine of normals and of stone-formers. Lancet. II:775-778.

6. Rose, M. B. 1975. Renal stone formation: the inhibitory effect of urine on calcium oxalate precipitation. Invest. Urol. 12:428-433.

7. Pak, C. Y. C., and R. A. Galosy. 1980. Propensity for spontaneous nucleatio of calcium oxalate. Am. J. Med. 69:861-989.

8. Pak, C. Y. C., K. Holt, J. Zerwekh, and D. E. Barilla. 1978. Effects of orthophosphate therapy on the crystallization of calcium salts in urine. Miner. Electrolyte Metab. 1:147-154.

9. Kitamura, T., J. E. Zerwekh, and C. Y. C. Pak. 1982. Partial biochemical and physicochemical characterization of organic macromolecules in urine from patients with renal stones and control subjects. Kidney Int. 21:379-386.

10. Ito, H., and F. L. Coe. 1977. Acidic peptide and polyribonucleotide crystal growth inhibitors in human urine. Am. J. Physiol. 233:F455F463.
11. Nakagawa, Y., H. C. Margolis, S. Yokoyama, F. J. Kézdy, E. T. Kaiser, and F. L. Coe. 1981. Purification and characterization of a calcium oxalate monohydrate crystal growth inhibitor from human kidney tissue culture medium. J. Biol. Chem. 256:3936-3944.

12. Nakagawa, Y., V. Abram, F. J. Kézdy, E. T. Kaiser, and F. L. Coe. 1983. Purification and characterization of the principal inhibitor of calcium oxalate crystal growth in human urine. J. Biol. Chem. 258: 12594-12600.

13. Nakagawa, Y., V. Abram, and F. L. Coe. 1984. Isolation of calcium oxalate crystal growth inhibitor from rat kidney and urine. Am. J. Physiol. 247:F765-F772.

14. Fleisch, H. Inhibitors and promoters of stone formation. 1978. Kidney Int. 13:361-371.

15. Coe, F. L. 1978. Nephrolithiasis, Pathogenesis and Treatment. Year Book Medical Publishers Inc., Chicago. 1-30.

16. Coe, F. L. 1980. Clinical stone disease. Contemporary Issues in Nephrology. F. L. Coe, B. M. Brenner, and J. H. Stein, editors. Churchill Livingstone, New York. 1-12.

17. Coe, F. L., and M. J. Favus. 1891. Disorders of Stone Formation. In The Kidney. B. M. Brenner and F. C. Rector, Jr., editors. W. B. Saunders \& Co., Philadelphia. 1950-2007.

18. Coe, F. L. 1977. Treated and untreated recurrent calcium oxalate nephrolithiasis in patients with idiopathic hypercalciuria, hyperuricosuria or no metabolic disorder. Ann. Intern. Med. 87:404-410.

19. Lowry, O. H., N. J. Rosebrough, A. L. Farr, and R. Randall. 1951. Protein measurement with the Folin phenol agent. J. Biol. Chem. 193:265-275.

20. Frucher, R. B., and A. M. Crestfield. 1965. Preparation and properties of two active forms of ribonuclease dimer. J. Biol. Chem. 240: 3868-3874.

21. Clamp, J. R., T. Bhatti, and R. E. Chamers. 1971. The determination of carbohydrate in biological materials by gas-liquid chromatography. Methods Biochem. Anal. 19:229-344.

22. Hauschka, P. V. 1977. Quantitative determination of $\gamma$-carboxyglutamic acid in proteins. Anal. Biochem. 80:212-223.

23. Katayama, L., L. H. Ericsson, D. L. Enfield, K. A. Walsh, H. Neurath, E. W. Davie, and K. Titani. 1979. Comparison of amino acid sequence of bovine coagulation coagulation factor IX (Christmas Factor) with that of other vitamin K-dependent plasma proteins. Proc. Natl. Acad. Sci. USA. 76:4990-4994.

24. Kuwada, M., and K. Katayama. 1981. A high performance liquid chromatographic method for the simultaneous determination of $\gamma$-carboxyglutamic acid and glutamic acid in proteins, bone and urine. Anal. Biochem. 117:259-265.

25. Bailey, J. L. 1962. Ultraviolet absorption of proteins. In Techniques in Protein Chemistry. Elsevier Science Publishing Co. Inc., New York. 295-296.

26. Adamson, A. W. 1976. Surface films on liquid substrates. In 
Physical Chemistry of Surfaces. Third ed. John Wiley \& Sons, New York. 99-195.

27. Stenflo, J., and J. W. Suttie. 1977. Vitamin K-dependent formation of $\gamma$-carboxyglutamic acid. Ann. Rev. Biochem. 46:157-172.

28. Hauschka, P. V., and M. L. Reid. 1978. Vitamin K dependence of a calcium binding protein containing $\gamma$-carboxyglutamic acid in chicken bone. J. Biol. Chem. 253:9063-9068.

29. Nelsestuen, G. L., M. Broderius, T. H. Zytovicz, and J. B. Howard. 1975. On the role of $\gamma$-carboxyglutamic acid in calcium and phospholipid binding. Biochem. Biophys. Res. Commun. 65:233-240.

30. Malhotra, O. P., M. E. Nesheim, and K. G. Mann. 1985. The kinetics of activation of normal and $\gamma$-carboxyglutamic acid-deficient prothrombins. J. Biol. Chem. 260:279-287.

31. Murray, A. C., and C. M. Kay. 1972. Hydrodynamic and optical properties of Troponin A. Demonstration of a conformational change upon binding calcium ion. Biochemistry. 11:2622-2627.
32. LaPorte, D. C., B. M. Wierman, and D. A. Storm. 1980. Calciuminduced exposure of a hydrophobic surface on calmodulin. Biochemistry. 19:3814-3819.

33. Lian, J. B., E. L. Prien, Jr., M. J. Glimcher, and P. M. Gallop. 1977. The presence of protein-bound $\gamma$-carboxyglutamic acid in calciumcontaining renal calculi. J. Clin. Invest. 59:1151-1157.

34. Spector, A. R., A. Gray, and E. L. Prien, Jr. 1976. Kidney stone matrix: differences in acidic protein composition. Invest. Urol. 13:387389.

35. Warpehoski, M. A., P. J. Buscemi, D. C. Osborn, B. Finlayson, and E. P. Goldberg. 1981. Distribution of organic matrix in calcium oxalate renal calculi. Calcif. Tissue Int. 33:211-222.

36. Bommer, J., E. Ritz, W. Tschope, R. Waldherr, and M. Gebhardt. 1979. Urinary matrix calculi consisting of microfibrillar protein in patients on maintenance hemodialysis. Kidney Int. 16:722-728. 